\title{
Difficulties of Educating People With Socio-Educational Needs
}

\section{Dificultades para educar a las personas con necesidades socioeducativas}

\section{Simonenko S.M.}

Far Eastern Federal University, Vladivostok, Russia ORCID: https://orcid.org/0000-0001-8510-712X

\section{Klyuchnikov D.A.}

Far Eastern Federal University, Vladivostok, Russia ORCID: https://orcid.org/0000-0002-0803-8383

\section{Yunevich M.N.}

Far Eastern Federal University, Vladivostok, Russia ORCID: https://orcid.org/0000-0002-0379-4075

\section{Suprunov S.E.}

Plekhanov Russian University of Economics, Moscu, Russia ORCID: https://orcid.org/0000-0002-6842-2723

\section{Kuprieva I.A.*}

Far Eastern Federal University, Vladivostok, Russia ORCID: https://orcid.org/0000-0002-1024-7053

*Correspondence

Email: kuprieva@yandex.ru
Cite as:

Simonenko, S. M., Klyuchnikov, D. A., Yunevich, M. N. Suprunov, S. E., \& Kuprieva I. A. (2020). Difficulties of Educating people with socio-educational needs, Propósitos y Representaciones, 8(2), e474. Doi: http://dx.doi.org/10.20511/pyr2020.v8n2.474 


\section{Summary}

The publication "Problems of introducing inclusive education in the social environment of Ussuriysk city" examines the complex problems and sociocultural processes of society concerning people with special socio-educational needs, people with disabilities and people with physical disabilities. The paper briefly explains the essence of inclusive education and the problems of its introduction into the social environment of small towns, for example, the city of Ussuriysk, when, along with the development of defectological schools and the government order for them, there is a lack of understanding of the need for such education, an indifferent, callous attitude towards disadvantaged physical disabilities to people.

Keywords: Inclusive Education; Children witth Special Socio-Educational Needs; SocioCultural Processes; Humanization.

\section{Resumen}

Este estudio examina los problemas complejos y los procesos socioculturales de la sociedad en relación con las personas con necesidades socioeducativas especiales, las personas con discapacidad y las personas con discapacidad física. El documento explica brevemente la esencia de la educación inclusiva y los problemas de su introducción en el entorno social de los pueblos pequeños, por ejemplo, la ciudad de Ussuriysk, cuando, junto con el desarrollo de escuelas defectológicas y el orden del gobierno para ellos, existe una falta de comprensión de la necesidad de tal educación, una actitud indiferente e insensible hacia las personas con discapacidades físicas desfavorecidas.

Palabras clave: Educación inclusiva; Niños con necesidades socioeducativas especiales; Procesos socioculturales; Humanización.

\section{Introduction}

At present, a person, his culture, education, scientific development, health, personal qualities are considered not only as a means, an instrument of a particular activity to transform nature and society, but above all as the goal, result, meaning of these transformations and the existence of society itself.

In the nineties of the last century in our country there was a reassessment of the role of the individual in the development of our society, where the MAN with all its unique properties and features became the center of theoretical understanding of social phenomena, which was associated with the processes of humanization, democratization, and increasing publicity (Gorshkova, 1991).

It was these processes that revealed one of the most difficult problems of our time - the problem of disability, attracting to it the attention of the general population of our country, including politicians, scientists, public figures, employees of secondary and higher schools (Kryuchkov, 2018).

Russia in the Soviet years, the 60s of the last century, first began to pay attention to the integration of special classes for children with moderate intellectual pathology in auxiliary schools that today belong to the group of schools for children with special social educational needs (SSEN).

Today, children with SSEN are children who have various mental and physical health abnormalities, causing impaired overall development, which do not allow children to lead a full life. The following definitions for such children can be synonymous with this concept: "children with problems", "children with special needs", "atypical children", "children with learning difficulties", "abnormal children", "exceptional children" (Filipova, 2015). We believe that the synonym for "children with special socio-educational needs" (children with SSEN) most fully reflects the problem of our research. 
Inclusive education (fr. Inclusif-inclusive, lat. Include-conclude, include, involve) is one of the processes of transformation of general education based on the understanding that people with disabilities in modern society can (and should) be involved in society.

This transformation is focused on creating conditions for accessibility of education for all, including providing access to education for children with disabilities (Ministry of Education and Science of the Russian Federation: Letter from February 2, 2016 N VC-163/07).

Inclusive education aims to develop a child-centric methodology (aimed at children and recognizing that all children are individuals with different learning needs). Inclusive education is trying to develop an approach to teaching and learning that will be more flexible to meet different learning needs. If teaching and learning become more effective as a result of the changes that inclusive education introduces, then all children will benefit (not only children with special needs).

More than 30 years after our country began to pay attention to the integration of special classes for children with SSEN, special attention was paid to the protection of the right to education at all levels of children with special socio-educational needs, where on the basis of the legal framework a document was published - Federal Law No. 181 of November 24, 1995 "On Social Protection of Disabled Persons in the Russian Federation".

Since the signing of this Federal Law in 1995 in Russia, at the legislative level, a child with SSEN has been assigned all the rights to education in accordance with an individual program of rehabilitation of a disabled person. But experts did not take into account the fact that there are not as many specialized educational institutions in the country as we would like. The fact is that the number of children with SSEN increases every year more and more. According to statistics, if in 2010 the number of children with SSEN was about 495 thousand, by the beginning of 2017 it was 628 thousand, these figures indicate the relevance of the direction of our research (Sadykova, 2018).

The implementation of this law becomes an acute problem in medium-sized cities, where the main factors hindering the implementation are poor financing, poor quality of health care, shortage of personnel as well as the society's unwillingness to accept citizens with physical and mental disabilities.

In Russia, the year 2018 has become special in the field of the development of inclusive education in the country. In April 2018, the Moscow International Salon of Education (MISE) was the largest event in Russia in the field of education, which was based on an open forum and a large-scale exhibition of educational technologies, where the fourth year past one of the key sections was the section on the education of children with SSEN (Turkey discusses an accessible university environment and inclusive education: the article).

In May 2018, the forth World Global Congress "Accessible University Environment and Inclusive Education" was held in Mersin (Turkey) where the Russian Federation took part for that period of time (before the reorganization of August 13, 2014) represented by the First Deputy Minister Education and Science of the Russian Federation V.V. Pereverzova (In Russia, a concept of the development of an inclusive and correctional education system for the period up to 2030 will appear: article).

In July 2018, under the Council of the Ministry of Education and Science of the Russian Federation (before the reorganization dated August 13, 2018) on the education of persons with disabilities and disabilities, the first meeting of the working group to develop a concept for the development of the educational system of students with disabilities and students with disabilities was held health, where the director of the Department of state policy in the field of the protection of children's rights is Silyanov stressed that there is a need to develop a strategic document defining goals, objectives, principles and main directions for the development of inclusive and remedial education in the Russian Federation for the period up to 2030 (Indole, 1998). 
All the above measures, laws and educational development programs show that the Ministry of Education of Russia is actively engaged in the development of educational institutions and the implementation of inclusive education in the social environment of Russian society.

However, in small cities such as the city of Ussuriysk (Ussuriysky urban district - UUD) (the number of residents is about 200 thousand people), the situation does not change at all, and even vice versa, becomes more acute and painful. This is due to the following, in our opinion, the main reasons:

- poor quality of health care and lack of specialist specialists in children are late diagnoses leading to disability,

- there are not enough correctional schools of all eight types (usually one or two schools out of eight types of schools work in a small town), and with some diagnoses, for example, autism syndrome, there is no distribution of such children at all, because they need special specialized centers;

- scant financing of medium-sized cities does not allow general educational institutions to re-equip their material base to receive children with SSEN. It is impossible to equip school buildings built back in the 60-70s of the twentieth century, to equip with wide doorways, ramps for wheelchair-bound children, and to build 2 or 3-storey schools with elevators, for blind children to build special gyms with special equipment and inventory, etc.

The main question remains, which constitutes one of the main problems of introducing inclusive education in the social environment: "Is the society ready to accept children with special socio-educational needs as equal citizens?"

In our opinion, the reasons given at the beginning of the work are more related to poor financing and control. But even if there is a good financing of schools, there will be equipment for integrated learning, it becomes clear and understandable that the last reason we designated as the main issue should not be discounted, since it is significant and influences the further result of the implementation of inclusive education in social environment. This determines the importance and relevance of our chosen study.

Object of study: the process of development of inclusive education in small cities (for example, UUD).

Subject of research: problems of introducing inclusive education in the social environment of Ussuriysk, Primorsky region.

Objective: to evaluate the development of inclusive education in UGO of Primorsky region.

\section{Objectives of the Study}

- To analyze information sources on the research problem, to identify the factors hindering the implementation of inclusive education in the social environment in the CSR of Primorsky region.

- Conduct a sociological survey among the population in the UGO of Primorsky region on the development of inclusive education.

- To identify the problems of introducing inclusive education in the social environment of the UUD of Primorsky region. 


\section{Methods}

Sociological (survey, questioning), pedagogical observation, pedagogical experiment, modeling, methods of mathematical statistics.

Scientific novelty of the research: the development of scientific and theoretical foundations for the development of an inclusive education system in the UUD of Primorsky region.

Practical significance: the results of the study can be used as statistical studies to identify and solve problems in the development and implementation of inclusive education in the general educational environment of the UUD of the Primorsky region.

The study presented in our work as subjects consisted of senior students of educational institutions of the Ussuriysk urban district (UUD) and an adult population with children of preschool and school age living in the UGO territory of Primorsky region.

To obtain current information on the implementation of inclusive education in the social and educational environment, in 2015-2018 we conducted surveys among senior students from various educational institutions (agronomists studying at the Ussuriysk agro-industrial college, nurses studying at the medical college, teachers studying at the Far Eastern Federal University, and the adult population with children of preschool and school age in the UUD. The study included 492 people, including 187 students from various educational institutions, 124 people adults whose children attend kindergarten, 181 people - parents, children who study at school and 9 people - parents, children who study in correctional school of the eighth type.

\section{Results}

In the article we will consider several questions from a variety of questionnaire and social survey questions which in our opinion are significant in our study.

To the question: "Is it necessary in our city, in your opinion, to create a social and educational environment in which all children, including those with disabilities, will be comfortable?" - we obtained the following results (Figure 1):

The 187 students surveyed, 109 people (58\%) answered that such an environment is necessary in the city. Of these, 12 people considered that the village also needs such a process, and 78 people $(42 \%)$ answered differently, but on the whole with a negative result.

Among parents whose children attend kindergarten - 124 people, 98 respondents (79\%) agreed on the need to create a comfortable environment for all children.

The 181 people, 115 people (64\%) - parents, children who study at school, also believe that the city needs to pay attention to such a special process that contributes to the positive formation of the personality of each child. In their opinion, it is necessary to introduce such an environment everywhere, since the birth rate in the city has grown, but there are also a lot of children with disabilities, they also need a quality education.

A survey of parents, children who study at the eighth type correctional school, showed that parents - 9 people (100\%) - support the creation of such an environment. And the main thing for them in this matter is the continuity of the school with vocational schools (colleges), which are enough in the city. But they stopped taking the graduates of the eighth type correctional school for study. 
Thus, out of 492 people. 331 respondents (67\%) of the respondents gave a positive answer to this question, and 161 people (33\%) - negative.

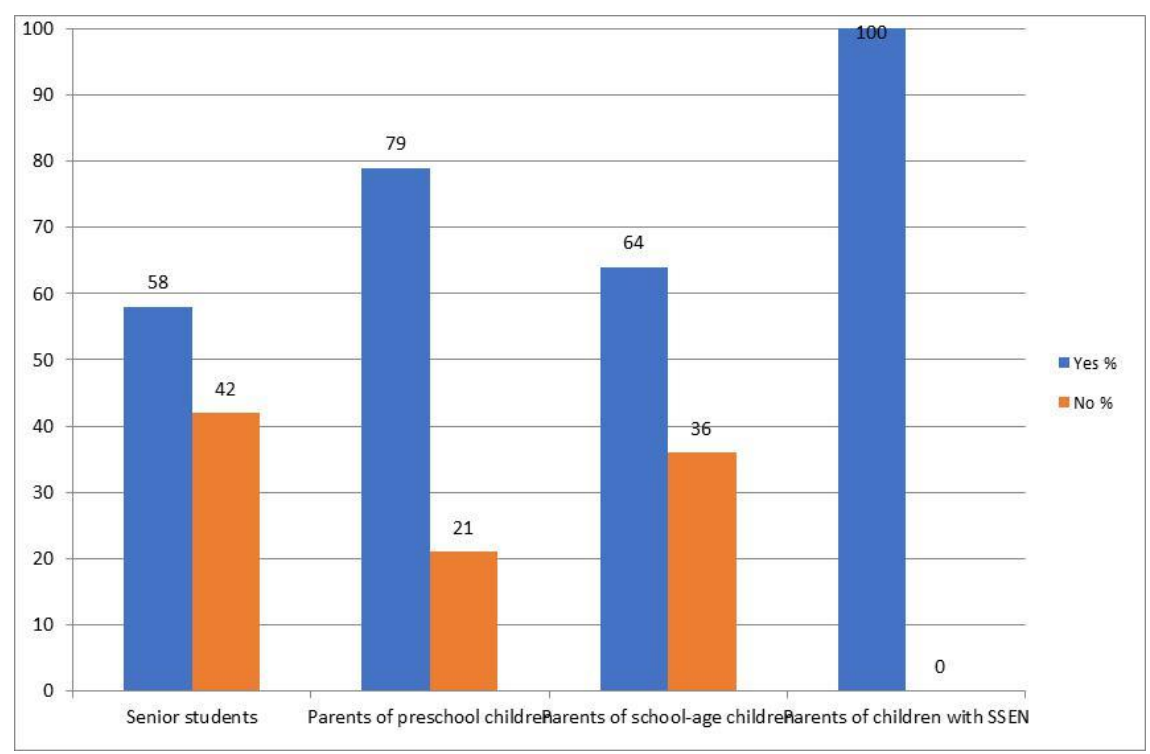

Figure 1. Results of the survey "Is it necessary in our city to create a social and educational environment in which all children will be comfortable, including those with disabilities?"

Parents with children of pre-school and school age and students were asked the question: "How would you react to the fact that children with SSEN will study at your educational institution?" (Figure 2).

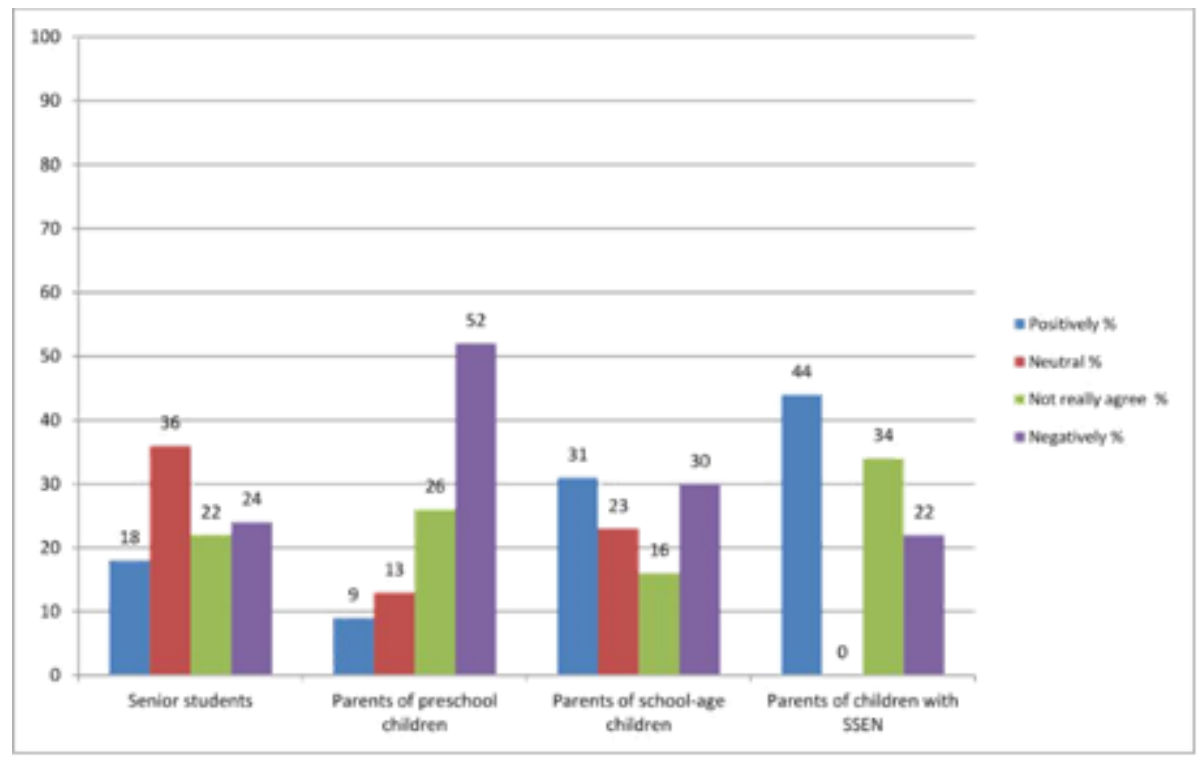

Figure 2. The results of the survey "How would you react to the fact that children with SSEN will study at your educational institution?"

Parents whose children attend pre-school educational institutions, 64 people (52\%) were against their children communicating with children with SSEN, since they believed that their 
children could learn from others a bad form of speech, stuttering, bad behavior, a walk, they would start to imitate and adopt nervous tics and so on . Of these, 33 people of the interviewed parents (27\%) explained their refusal by the conditions of optimization which has covered the education system on a large scale lately. In their opinion, all the attention of the teaching staff will be given to children with SSEN and their children will be left without proper attention. Parents who responded to this idea with the answer "not very" - 32 people (26\%) also hold the opinion that the optimization process will lead to an increase in payment for kindergarten. Only 11 parents (9\%) reacted positively to these changes and 17 parents (13\%) remained indifferent to this process.

Parents of children studying at school reacted differently to this issue: 57 people (31\%) agreed with inclusive reforms at school, but only if children with SSEN do not study all together but in specialized classes in a separate territory schools and funding will come from budget allocations. 54 people of the parent (30\%) reacted negatively, explaining his answer to the fact that the payment for school will increase, that the school will lose its main goal: quality education, etc. 29 parents (16\%) also did not see anything good in this, and 41 respondents (23\%) refrained from commenting, did not find what to say, remained neutral.

Of the 9 people with parents of children with SSEN the answer was given as follows: 4 people (44\%) supported this idea, commenting that their children may have friends and they will have many-sided communication, 2 people $(22 \%)$ reacted negatively to this to the process, since "today's generation of children is very aggressive and they can only harm children with SSEN", 3 people (34\%) see in this process both good and bad.

The opinion of the students was divided as follows: 67 people (36\%) remained neutral, commenting that "let them learn, they will not interfere with us", 34 people $(18 \%)$ agreed and 44 respondents $(24 \%)$ were against - in their opinion, Let children with special socio-educational needs study, but somewhere in other specialized educational institutions, and not together with everyone. You can quote their answer: "they will need to constantly take care of and help them."

In our opinion, another important issue in this study is for parents: "If children who have special social and educational needs who need support from others are brought up in an educational institution where your child studies, then how will you feel to the fact that your child will assist in helping children with SSEN during extracurricular activities (at preschool age is this frequent communication with children with SSEN)" (Figure 3).

For parents with SSEN the question was asked as follows: "How would you react to the fact that your child will receive different types of help from healthy peers?"

For students, the question was: "Will you assist your peers with SSEN in helping you study outside of the classroom?" 


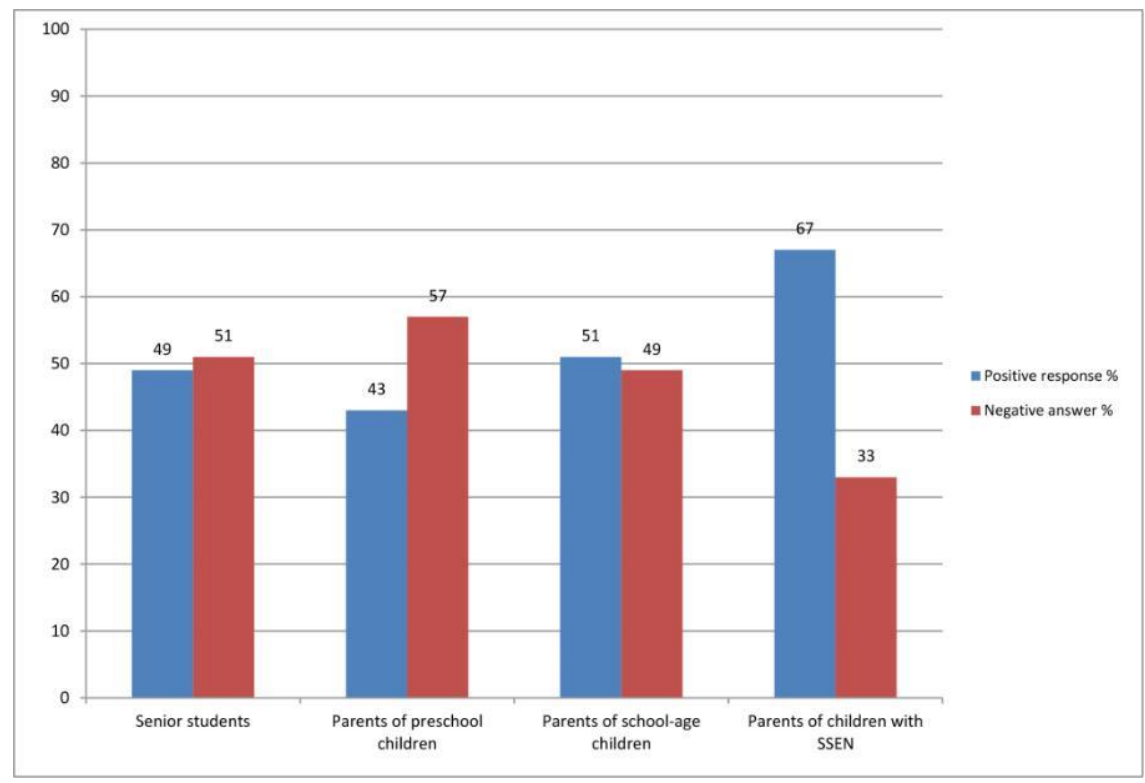

Figure 3. The results of the survey on communication and assistance in helping children with SSEN

This question has caused many contradictions among respondents to the introduction of inclusive education in their environment; many of them were not ready to accept this process. So, 96 students (51\%) and 71 parents of preschool children (57\%) refused to introduce inclusive education in their educational institutions. The students, on the whole, explained that they didn't have much time to spray it on other, in their opinion, unplanned events. They believe that they have so little time to prepare for the next class. Then the question was reformulated to this group differently. "If a peer with SSEN turns to you for help, how will you act? Deny him or not? ". Here 96 respondents $(51 \%)$ divided into two groups: 45 people $(24 \%)$ answered that they would still help, and 51 people (27\%) stayed with their opinion indicated earlier.

Parents of preschool children have explained their negative answer by the fact that at this age children take up a lot from others, constant communication with children with OSON can lead to problems of physical, mental and social health of their children.

Parents of school-aged children 89 people (49\%) reacted negatively to the introduction of inclusion in the school where their children study. However, their number is slightly lower compared to the number of parents who approved the introduction of inclusion in their school is 92 people $(51 \%)$. We see that the number of those and others is almost equal which already suggests that parents of school-age children are more confident in their children and are not afraid for them, like parents of preschool children. They have a completely different plan of concern. Parents explain their answers to the fact that they are not particularly satisfied with the fact that their child will be burdened with the problems of other children, because he has a lot of his affairs and activities, for which he must also have time to prepare. But they also do not refuse to let the child help children with SSEN, but just let it be inconstant and impermanent.

In all groups, positive results were commented on with practically the same phrase: "Helping is good, why not."

Parents of children with SSEN were more inclined to respond positively to 6 people $(67 \%)$, since the word "help" attracted their attention. In it, they saw the process of 
communicating with other peers, not like their child, gaining new experience in an educational environment, more knowledge, etc. Negative answers also didn't go off: people (33\%).

This survey showed that for the most part the society lives in different reality: if at the beginning of the survey, where it was a question of theoretical introduction inclusive education in the social environment of the city, most approved this the process, when it came to its practical part, began to manifest itself in the answers negative trend.

Thus, as we see future specialists are morally and psychologically not yet ready for integrated education of children with disabilities in development, and the adult population does not really delve into the concept and objectives of implementation inclusive education in the social environment of our society. Main the arguments are the health of their own children and the fact that all changes in the direction of introducing an inclusive education system will be on the shoulders of parents who have healthy children.

\section{Conclusion}

In conclusion, we can say that our state is trying to do everything possible that persons with special socio-educational needs felt like full citizens of their country. Positive the results are visible in large cities, and what should people living in small cities where society faces problems like poor funding, low health, lack of specialists, low income level of the population, unemployment.

But if a solution can be found here only in the assistance of federal bodies then, in our opinion, persons with special social and educational needs are faced with one of the terrible, weighty problems "to be misunderstood in their society", "to be strangers among their own". And our the study reflected this fact in the results, where the positive answers are not very prevailed over negative.

At present, still in our country society is not ready to accept people with disabilities as equal to themselves citizens, citizens who like others, have the right to develop their abilities and opportunities, work and live a full life. Many professionals implementing inclusive education in schools note that the main problem of introducing mass inclusion today is misunderstanding our society that is people.

Thus, considering the shortcomings of the implementation of the inclusion model in the social and educational environment in a small town can be noted that the main problem is a public misunderstanding of this phenomenon, the roots of which go to the recent Soviet past of our state. Although today we observe that our society is still gradually acquiring the features of a "new humanism ", it puts in the center of the person with emerging new qualities (global thinking, love of justice, aversion to violence and creating a single community of equal people). This is also evident in this study: our subjects were often divided into groups with almost equal indicators of positive and negative results. It all makes us review and re-evaluate ideas about a barrier-free world for people with special needs social educational needs. Accepted cultural norms of society lead to the realization of the idea of the value and uniqueness of each person and this contributes to a sharp increase in humanistic aspirations in supporting people, especially children with special socio-educational needs.

In our opinion, in order to make a difference in the UUD and other small cities, in views and attitudes in the minds of those people opposed the processes of introducing inclusion in the social and educational environment, it is necessary to did create or open at least one such school in the city. For students, students in various types of educational institutions, the curriculum needs introduce a subject that would reveal the essence of inclusive education (in Far Eastern Federal University (FEFU) in preparing future. 
There is such a discipline for teachers, and FEFU students who participated in research, almost all supported inclusive education).

After all, in the future young professionals - potential parents, they will drive their child to kindergarten, and then to school. With the adult generation that survived the Soviet era, it is also necessary conduct conversations, assist them. Often, they are largely their opinion and authority affect the younger generation. It is therefore necessary at present today pay attention to the upbringing and education of parents who already have today, children of preschool and school age as well as future parents.

In this they should be helped by educators, educators, psychologists, they can spend various courses or parental education for the promotion and promotion inclusive education in a social environment with the involvement of volunteer movements currently available in FEFU and working for the benefit of societies in such a small city as Ussuriysk.

Thus, the introduction of inclusive education in the social environment will always depend not only on the scientific views of its creators, political installations, economic opportunities of the state but also from accepted cultural norms of society, its upbringing and education.

\section{References}

Filipova, E. V. (2015). Children with special needs: report. [Electronic resource]: All-Russian online publication "Preschooler" (Kindergarten. RF)

Gorshkova, V. V. (1991). The problem of the subject in pedagogy [Text]. Leningrad, -S.4. In Russia, a concept of the development of an inclusive and correctional education system for the period up to 2030 will appear: article [Electronic resource]. (2018). Ministry of Education of Russia (official website).

Indole, L. N. (1998). As it was [Text] / L.N. Indole. - M.: Awareness, pp. 13-28.

Kryuchkov, D. A. (2018). Some problems of the development of inclusive education in Russia [Electronic resource]. D.A. Kryuchkov. - X International Student Scientific Conference "Student Scientific Forum 2018"

Ministry of Education and Science of the Russian Federation: Letter from February 2, 2016. NVC163/07 [electronic resource].

Sadykova, A. (2018). What happens to inclusive education in Russia?: article [Electronic resource]. A. Sadykov. - El. magazine "Such things".

Turkey discusses an accessible university environment and inclusive education: the article (2018). The newspaper "Dawn of Youth". 